\title{
Occurrence of Pasteurella multocida in Dogs Being Trained for Animal-Assisted Therapy
}

\author{
Antonio Santaniello ${ }^{1, *(1)}$, Susanne Garzillo ${ }^{1}$, Alessia Amato ${ }^{1}$, Mario Sansone ${ }^{2, *(\mathbb{D} \text {, }}$ \\ Alessandro Fioretti ${ }^{1}$ and Lucia Francesca Menna ${ }^{1}$ \\ 1 Department of Veterinary Medicine and Animal Productions, Federico II University of Naples, \\ 80134 Naples, Italy; susannegarzillo@gmail.com (S.G.); alessiaamatovet@gmail.com (A.A.); \\ fioretti@unina.it (A.F.); menna@unina.it (L.F.M.) \\ 2 Department of Electrical Engineering and Information Technology, Federico II University of Naples, \\ 80125 Naples, Italy \\ * Correspondence: antonio.santaniello2@unina.it (A.S.); mario.sansone@unina.it (M.S.); \\ Tel.: +39-081-253-6134 (A.S.); +39-081-768-3807 (M.S.)
}

Received: 21 July 2020; Accepted: 30 August 2020; Published: 2 September 2020

\begin{abstract}
Animal-assisted therapy (AAT) is a non-pharmacological therapy aimed at people with physical and/or mental disabilities. Therefore, it is necessary to carry out interventions that guarantee its benefits for patients while also avoiding the risk of zoonoses due to contact with the animals or their mucous membranes. The present study aimed to detect the occurrence of Pasteurella multocida in the oral cavity of dogs attending a "dog educational centre" and training for AAT interventions. In addition, some of the potential predictable factors of infection (i.e., age, sex, breed, and living conditions) were analyzed. In total, $25 / 200$ dogs examined ( $12.5 \%$; $95 \%$ confidence interval $=8.4-18.1 \%$ ) were positive for P. multocida, as confirmed by PCR. Sex, breed, and living conditions were risk factors associated with P. multocida as revealed by the logistic regression analysis. Specifically, cross-bred female dogs living prevalently outdoors were significantly associated with the presence of P. multocida $(p<0.05)$. This study represents the first epidemiological survey of the prevalence of P. multocida in the oral cavity of dogs involved subsequently in AAT interventions, highlighting the potential risk of $P$. multocida infection in patients, often belonging to risk categories (e.g., children, the elderly, and immunocompromised individuals). Therefore, healthcare guidelines could be suggested to integrate the current literature related to the health check of dogs involved in AAT. In this way, it could be ensured that, even with bodily contact during AAT, the risk of pathogen transmission by the co-therapist dog can be avoided.
\end{abstract}

Keywords: animal-assisted interventions; co-therapist dogs; zoonosis; patients; risk factors; contact

\section{Introduction}

The human-animal bond is considered as "a mutually beneficial and dynamic relationship between people and animals that is influenced by behaviors that are essential to the health and well-being of both" [1]. Likewise, the connection with other living organisms (i.e., biophilia) is considered a fundamental biological human need [1]. As is known, dogs generously contribute to many aspects of medicine and their relationship with humans is becoming ever closer, more frequent, and important-particularly concerning physical as well as psychological benefits [2-4]. In this regard, dogs also play a central role in animal-assisted therapy (AAT) as co-therapists or as a support for people with physical or mental health problems. Animal-assisted therapy is a goal-oriented, planned, and structured therapeutic intervention which is directed and/or delivered by health, education, and human service professionals (e.g., psychologists) and focuses on the socio-emotional functioning 
of the patients, either in a group or individual setting [5]. Usually, these therapeutic interventions are performed in healthcare facilities and are addressed to patients with mental or physical distress, depression, dementia, autism, or other illnesses [6-8]. During AAT, patients (usually young, old, or immunocompromised people) interact with dogs through different activities of an interspecific nature (i.e., petting, brushing, leading on a leash, hiding a ball, etc.) [4]. In this regard, Shen et al. [9] showed that bodily contact significantly influenced the effectiveness of AAT. On the other hand, during these interventions, because of repeated contact with the dog's mucosae (e.g., mouth mucosa), patients can be exposed to zoonotic pathogens (e.g., bacteria, viruses, and fungi) transmitted by the dog through direct contact [3,10-17]. Several reports describe human P. multocida infections acquired subsequent to close contact with a dog, such as sharing a bed or by licking or sniffing $[10,16,18]$. P. multocida is part of the normal mouth microbiota of mammals; in dogs, its oropharyngeal colonization rates range from $50 \%$ to $66 \%$ [15]. Zoonotic transmission usually occurs through a bite from a dog and by contact with the animal's saliva or nasal secretions [19-21]. Although cases of P. multocida infection have been reported more often in people from risk categories, such as young children, the elderly, pregnant women, or immunocompromised individuals [22], case reports of infection have also been reported in immunocompetent subjects [23-26]. In humans, P. multocida can cause serious infections, both invasive and localized, in the oral cavity, respiratory tract, and soft tissue, including pharyngitis, sinusitis, meningitis, tracheobronchitis, pneumonia, empyema, and abscess [10,18,23-30].

Considering that bodily contact is the main way to ensure the efficacy of AAT, with the high prevalence of $P$. multocida in the mouth microbiome of dogs and the possibility of transmission during the interaction time in the setting, the present study was carried out in order to evaluate the prevalence of P. multocida in the oral cavities of dogs in training for future interventions of AAT; in addition, the study aimed to evaluate whether age, sex, breed, and living conditions may represent predictable factors for the presence of this bacterium in the oral cavity of the dog.

Our evidence could be useful to suggest new guidelines regarding health protocols of dogs involved in AAT by integrating the information from current literature. In this way, bodily contact and other activities with dogs during AAT may be ensured while avoiding the risk of pathogens, such as P. multocida, being transmitted.

\section{Materials and Methods}

\subsection{Sampling}

The present study was performed from May to November 2018 on 250 dogs attending a dog educational centre in Southern Italy. As a preliminary step, the owners were interviewed using a pretested, standardized questionnaire to obtain a full history for each dog. The questionnaire was divided in two main parts: the first part included details on the animal's age, sex, breed, and living conditions, whereas the second concerned the medical history of the dog (Supplementary Materials).

A homogeneous sample of 200 healthy and not neutered dogs (based on the second part of questionnaire) was classified by several categories: two age groups, one representing animals ranging from three to twelve months old $(n=30)$ and the other representing animals over twelve months $(n=170)$; two sex groups-male $(n=125)$ and female $(n=75)$; two breed groups-crossbred $(n=110)$ and purebred $(n=90)$; two living conditions groups-indoor $(n=142)$ and outdoor $(n=58)$. Each dog was individually sampled using sterile, cotton-tipped swabs in the oral cavity (palate, internal gums and teeth, and tongue). All of the sampled dogs showed an absence of a periodontal procedure.

The animals examined in this study were sampled upon approval by the Animal Ethics and Welfare Committee of the University of Naples Federico II (protocol number 10418/03 February 2014).

\subsection{Isolation and Characterization of P. multocida}

Oral swab samples were collected from the animals and immediately inoculated onto blood agar supplemented with $2 \mu \mathrm{g} / \mathrm{mL}$ clindamycin, and then incubated aerobically at $37^{\circ} \mathrm{C}$ for $24 \mathrm{~h}$. 
All oxidase-positive, catalase-positive, and small Gram-negative rods or coccobacilli observed under the light microscope were sub-cultured. The identification of P. multocida colonies was first performed biochemically [31,32], and then confirmed colonies were picked for DNA extraction using the PrepMan sample reagent (PE Applied Biosystems), following the manufacturer's protocol. For P. multocida PCR identification, a pair of primers (Eurofins) were used: KMTJB-for TGCCACTTGAAATGGGAAATG and KMTJB-rev AATAACGTCCAATCAGTTGCG, (available in GenBank) encoding the outer-membrane protein (KMT-1) [33]. The reaction mixture $(50 \mu \mathrm{L})$ contained $2 \mu \mathrm{L}$ of mix oligos, $25 \mu \mathrm{L}$ of MyTaq Red Mix (Bioline), and $2 \mu \mathrm{L}$ of DNA. In total, forty PCR cycles of denaturation at $95{ }^{\circ} \mathrm{C}$ for $1 \mathrm{~min}$, annealing at $57^{\circ} \mathrm{C}$ for $15 \mathrm{~s}$, and elongation at $72{ }^{\circ} \mathrm{C}$ for $10 \mathrm{~min}$ were performed in a Model 9600 thermal cycler (PE Applied Biosystems). The PCR products were separated by electrophoresis on $1.8 \%$ agarose gel (Gibco-BRL), stained with ethidium bromide, and visualized under UV light, and the results were recorded using a Chemilmager 5500 (BSI). PCR amplified without DNA was used as a negative control, whereas reference P. multocida strains ATCC 43137 were used as positive controls (LGC Promochem).

\subsection{Statistical Analyses}

The chi-square test was used as a statistical method to determine whether age, sex, breed and living conditions were predisposing factors for P. multocida positivity. Furthermore, the Cochran-Mantel-Haenszel test was used for the independent variables that showed significance $(p<0.05)$ as well as to obtain an adjusted odds ratio (OD) with a $95 \%$ confidence interval (CI). Statistical analyses were performed in $\mathrm{R}[34,35]$. Moreover, to gain insight into the different factor combinations affecting positivity for P. multocida, we performed a logistic multivariate regression [36] over all of the factors (age, sex, breed, and living conditions) in order to identify significant predisposing factor combinations with the following formula:

$$
\log [p /(1-p)]=\beta 0+\beta 1 \times \text { sex }+\beta 2 \times \text { breed }+\beta 3 \times \text { living conditions }+\beta 4 \times \text { age }
$$

where $\mathrm{p}$ is the probability to be positive for P. multocida; $\beta \_\mathrm{i}$ are the regression coefficients; coding of the factors was the following: female $=0$, male $=1$; cross-breed $=0$, pure-breed $=1$; indoor $=0$, outdoor $=1$; young $=0$, old $=1$. This analysis was carried out in $R[34,35]$.

\section{Results}

Out of the 200 dogs examined, 25 subjects $(12.5 \%$; 95\% confidence interval $(\mathrm{CI})=8.4-18.1 \%)$ were positive for P. multocida, as found by the biochemical identification and then confirmed by PCR. As shown in Table 1, female dogs showed a high prevalence for P. multocida of $22.7 \%$, whereas male dogs showed a prevalence of $6.4 \%$. This difference was statistically significant $(p<0.05)$. Moreover, crossbred dogs showed a prevalence of $18.8 \%(95 \% \mathrm{CI}=14.0-23.5 \%)$ for $P$. multocida, whereas purebred dogs showed a prevalence of $5.6 \%(95 \% \mathrm{CI}=3.0-9.5 \%)$; this difference was statistically significant $(p<0.05)$. Finally, dogs living outdoor showed a prevalence of $22.4 \%(95 \% \mathrm{CI}=6.5-11.0 \%)$ for P. multocida, whereas dogs living indoors showed a prevalence of $8.4 \%(95 \% \mathrm{CI}=15.0-31.5 \%)$; this difference was statistically significant $(p<0.05)$. In contrast, there was no significant difference related to age $(p>0.05)$. With respect to the Cochran-Mantel-Haenszel test results, sex and living conditions were potential predictable risk factors for P. multocida positivity (Table 2).

Regarding the logistic regression analysis, the results confirmed that age was not a predictable risk factor (old dogs: $21 / 170=0.12$; young dogs: $4 / 30=0.13, p>0.05$ ). On the contrary, sex, breed, and living condition factors showed significant predictable risk values as reported in the corresponding computed coefficients and $p$-values in Tables 3 and 4 . It should be highlighted, for example, that habitat is the most important factor because outdoor living can almost triplicate the OR (associated term in Table 3 is 2.870). In summary, P. multocida positivity matched with high probability in female, cross-bred, outdoor dogs $(p<0.05)$. 
Table 1. Detailed sampling data of the dogs (age, sex, breed, and living conditions) and related positivity to $P$. multocida.

\begin{tabular}{|c|c|c|c|c|}
\hline Dogs Data & No. of Samples & No. of Positive Samples (\%) & $\mathrm{CI}^{+}(95 \%)$ & $p^{*}$ \\
\hline \multicolumn{5}{|l|}{ Age } \\
\hline 3-12 months & 30 & $4(13.33)$ & $6.0-25.5$ & $>0.05$ \\
\hline$>12$ months & 170 & $21(12.35)$ & $11.30-14.5$ & \\
\hline \multicolumn{5}{|l|}{ Sex } \\
\hline Female & 75 & $17(22.7)$ & $16.5-30.5$ & 0.001 \\
\hline Male & 125 & $8(6.4)$ & $4.5-9.5$ & \\
\hline \multicolumn{5}{|l|}{ Breed } \\
\hline Crossbred & 110 & $20(18.8)$ & $14.0-23.5$ & 0.01 \\
\hline Purebred & 90 & $5(5.6)$ & $3.0-9.5$ & \\
\hline \multicolumn{5}{|c|}{ Living conditions } \\
\hline Outdoor & 58 & $13(22.4)$ & $15.0-31.5$ & 0.01 \\
\hline Indoor & 142 & $12(8.4)$ & $6.5-11.0$ & \\
\hline
\end{tabular}

Table 2. Cochran-Mantel-Haenszel test.

\begin{tabular}{cccccc}
\hline Independent Variable & Standard Error & $p$ Value & Odds Ratio & \multicolumn{2}{c}{$\mathbf{9 5 \% \text { Confidence Interval }}$} \\
\cline { 5 - 6 } $\begin{array}{c}\text { Sex } \\
\text { Female vs. Male }\end{array}$ & 0.45 & 0.001 & 4.28 & 1.74 & How \\
\hline $\begin{array}{c}\text { Living conditions } \\
\text { Outdoor vs. indoor }\end{array}$ & 0.43 & 0.01 & 3.13 & 1.33 & 7.35 \\
\hline
\end{tabular}

Dependent variable is $P$. multocida positivity.

Table 3. Logistic regression coefficients and corresponding $p$-values.

\begin{tabular}{|c|c|c|c|c|}
\hline & $\beta 0$ & $\beta 1$ (Sex) & $\beta 2$ (Breed) & $\beta 3$ (Living Conditions) \\
\hline coefficient & -1.151 & -1.496 & -1.382 & 1.054 \\
\hline$p$ & 0.003 & 0.002 & 0.01 & 0.02 \\
\hline $\exp ($ coefficient) & 0.316 & 0.224 & 0.251 & 2.870 \\
\hline
\end{tabular}

Coefficients $\beta \_\mathrm{i}$ in the first row are not directly interpretable, therefore, in the third row, we reported the corresponding odds ratio (OR):

$$
\left[\exp \left(\beta \_\mathrm{i}\right)=\mathrm{p} /(1-\mathrm{p})\right]
$$

Specifically, $\exp \left(\beta \_0\right)$ is the OR corresponding to the factor combination of female/cross-bred/indoor (see first row in Table 4); when considering other factor combinations, the term $\exp \left(\beta \_0\right)$ must be multiplied by the $\exp \left(\beta \_i\right)$ if the $i$-th factor is coded with 1 (e.g., when considering male/cross-bred/indoor (see second row in Table 4 ), the OR is given by $\exp (\beta 0)^{*} \exp (\beta 1)$ because male is coded with 1 ).

Probabilities are estimated by means of counts and number of actual positives clustered with the expected number of positives. 
Table 4. Height factor combinations and corresponding odds ratio (OR) and probabilities (normalized to interval 0-1) predicted with the logistic model.

\begin{tabular}{ccccccccc}
\hline Sex & Breed $^{*}$ & $\begin{array}{c}\text { Living } \\
\text { Conditions }\end{array}$ & $\begin{array}{c}\text { Predicted } \\
\text { Probability }\end{array}$ & $\begin{array}{c}\text { Estimated } \\
\text { Probability }(\mathbf{C I}) * *\end{array}$ & Count & $\begin{array}{c}\text { Actual } \\
\text { Positives }\end{array}$ & $\begin{array}{c}\text { Expected } \\
\text { Positives }\end{array}$ & OR $^{+}$ \\
\hline $\mathrm{F}$ & $\mathrm{C}$ & Indoor & 0.240 & $0.230(0.090,0.436)$ & 26 & 6 & 6.245 & 0.316 \\
\hline $\mathrm{M}$ & $\mathrm{C}$ & Indoor & 0.066 & $0.061(0.013,0.169)$ & 49 & 3 & 3.240 & 0.071 \\
\hline $\mathrm{F}$ & $\mathrm{P}$ & Indoor & 0.073 & $0.125(0.027,0.324)$ & 24 & 3 & 1.763 & 0.079 \\
\hline $\mathrm{M}$ & $\mathrm{P}$ & Indoor & 0.017 & $0(0.000,0.082)$ & 43 & 0 & 0.751 & 0.018 \\
\hline $\mathrm{F}$ & $\mathrm{C}$ & Outdoor & 0.476 & $0.400(0.163,0.677)$ & 15 & 6 & 7.136 & 0.907 \\
\hline $\mathrm{M}$ & $\mathrm{C}$ & Outdoor & 0.169 & $0.250(0.087,0.491)$ & 20 & 5 & 3.378 & 0.203 \\
\hline $\mathrm{F}$ & $\mathrm{P}$ & Outdoor & 0.185 & $0.200(0.025,0.556)$ & 10 & 2 & 1.855 & 0.228 \\
\hline $\mathrm{M}$ & $\mathrm{P}$ & Outdoor & 0.048 & $0(0.000,0.247)$ & 13 & 0 & 0.631 & 0.051 \\
\hline & & & Total & & 200 & 25 & & \\
\hline
\end{tabular}

${ }^{*}$ C: crossbred; P: purebred; ${ }^{* *}$ Confidence interval; ${ }^{+}$Odds ratio.

\section{Discussion}

The present study represents the first evaluation of the presence of P. multocida in the oral cavity of dogs being trained for AAT, in order to avoid the risk of zoonotic transmission to patients involved in this non-pharmacological therapy. The findings of the present study showed that P. multocida was isolated in 25/200 dogs attending a dog educational center. Particularly, sex (female vs. male) and living conditions (outdoor vs. indoor) were significant risk factors for P. multocida positivity as shown in Table 2. According to the results of our logistic regression analysis (reported in Tables 3 and 4), the match of female/cross-bred/outdoor dogs showed high probability in the epidemiology of P. multocida infections. In our opinion, higher positivity in female dogs $(22.7 \%)$, was not clearly understood considering the lack of data present in the literature. We can only hypothesize that the periodic change in the physiology of the reproductive apparatus of females and the different behavioral set with respect to males could be predisposing factors to be further explored. Regarding the greater positivity of crossbreed dogs $(18.8 \%)$, it is not possible to give a motivation that has scientific support. The higher prevalence of $P$. multocida in dogs living outdoors (22.4\%), might be related to the possible repeat contact with excreta of other vector animals (i.e., birds, rodents, or wild mammals) [37]. Contrasting data concerning P. multocida prevalence in the oral cavity of dogs involved in animal-assisted interventions were reported in the literature. Guay D.R. [15] reported the prevalence of P. multocida in the oral cavity of dogs, with a range from $50 \%$ to $66 \%$. Meanwhile, Lefebvre et al. [16] showed the presence of 7/102 (6.9\%) positive samples in dogs visiting hospitalized people in Ontario. Although it is difficult to speculate on these data, we can only hypothesize that different factors, such as geographic area, recent changes in the eating and hygiene habits of dogs, the method of sampling, and methods of bacterial identification, may have influenced the different prevalence of each study. In contrast, our study represents the first evaluation of P. multocida risk infection in dogs being trained as co-therapists in AAT. In fact, this non-pharmacological therapy has been performed in healthcare settings such as hospitals or healthcare facilities and is often aimed at patients belonging to risk categories (e.g., dialysis patients, Alzheimer's disease patients, and immunosuppressed or immunocompromised patients) [7,38-40]. In line with the current literature, the zoonotic risk is much higher for immunocompromised people but is also present for immunocompetent people [23-25,41]. In recent scientific literature, different case reports of transmission to humans through licking and other forms of contact with dogs have been reported. Ryan and Feder [27] reported a case of meningitis from P. multocida in a 12-day-old child due to frequent licking by house dogs. The authors point out that contact with a dog's saliva by licking can result in exposure to commensal organisms from its oral cavity, such as P. multocida or other bacteria. Navarro-Navajas et al. [21] described a clinical case of $P$. multocida bacteremia in an 88-year-old male 
patient who became infected by contact with a dog's saliva, with whom he shared food. The authors suggested maintaining a high degree of attention especially for immunocompromised patients when they are in contact with pets. Zarlasht and Khan [26] presented a case of P. multocida bacteremia that occurred following contact with a dog's saliva in a 61-year-old immunocompetent male subject. Therefore, the authors recommended considering this organism as a differential diagnosis not only in immunocompromised patients, but also in immunocompetent patients. Maraki et al. [25] described a case of a P. multocida infection in a 57-year-old immunocompetent male adult who had a decubitus ulcer of the lower limbs, emphasizing the need to avoid contact between the wound and the saliva of dogs. Abreu et al. [28] reported the case of a urinary tract infection by P. multocida in an 83-year-old male person. In addition, they performed a molecular genetic analysis of the P. multocida strains obtained by the patient and his dog, strongly suggesting a zoonotic transmission of this bacterium. Bardou et al. [24] reported a case of P. multocida meningitis in a 25-year-old immunocompetent woman through contact with her dog's saliva. Although the reported cases of infection are all individual, of the P. multocida infections, we underlined the variety of infected people (i.e., age, gender, immune status) and their respective clinical conditions.

Even in AAT, the patients involved have very different characteristics both in terms of age and, above all, in the type of disease (e.g., Alzheimer's, autism, depression, ADHD, and others).

Considering the few data and more generic guidelines often referenced in the scientific literature, our findings might serve to enrich the general recommendations for the health control of dogs and related risk assessment in the field of AAT [42-45]. In addition, given the prevalence of P. multocida found in our study $(12.5 \%)$ and considering the close and necessary contact between co-therapist dogs and patients, we recommend applying some simple rules of hygiene and behavior: perform a microbiological analysis approach of the oral cavity in all animals involved in AAT as a sane screening procedure to preserve the health of patients; keep the dog indoors by avoiding uncontrolled external access, especially in the days preceding the AAT sessions; disinfect the dog's coat and especially the mouth and nostrils (through wipes or patented preparations for the dog); pay attention to the game equipment and tools that are brought into the setting; avoid contact with other dogs or other animal species whose clinical history is unknown.

Limits

Our epidemiological investigation has some weaknesses since it only addressed P. multocida presence when there are other bacterial species of commensal zoonotic agents in the oral cavities of dogs (i.e., Capnocitophaga canimorsus); the number of dogs sampled was not very large and, at the time of sampling, the subjects were still in training or being selected; only four predictable infection factors (i.e., age, sex, breed, and living conditions) were considered; antibiotic sensitivity tests of isolated strains were not performed; the sampling was not repeated despite suggestions and corrections on lifestyle habits to limit the possibility of infection from the environment.

\section{Conclusions}

The dog represents the species most frequently involved in Animal-assisted Interventions (AAIs) and, particularly, in AAT. Knowing that its health status is an essential way to protect both the health of patients and the well-being of the animal itself, specific health checks targeting zoonotic pathogens, which are sometimes underestimated, should be standardized and become routine for co-therapist dogs who must interact with patients or people in a healthcare setting. In addition, it is important to detect $P$. multocida infections as they represent a latent risk in the case of contact with patients who are co-infected during AAT, considering that serious and systemic infections are not only determined by bites and scratches but also by contact with animal secretions, which are a potential transmission source.

Therefore, by our findings, dogs that are considered to be at high risk of P. multocida infection (i.e., female, crossbred, outdoor housed) should be screened for infection as a priority alongside the other hygiene measures listed above. 
Obviously, our evidence is not intended to represent a deterrent to carrying out AAT with dogs but an invitation to work with them carefully, allowing interaction with the animal while respecting the safety of the setting. Therefore, clear general hygiene rules should be reported and strictly applied, particularly in the setting of AAT.

Supplementary Materials: The following are available online at http://www.mdpi.com/1660-4601/17/17/6385/s1, Health questionnaire and life habits of the dogs.

Author Contributions: Conceptualization, A.S. and L.F.M.; methodology, A.S.; software, M.S.; formal analysis, M.S.; investigation, A.S., S.G. and A.A.; data curation, A.S.; writing-original draft preparation, A.S., S.G. and A.A.; writing-review and editing, A.S., A.F. and L.F.M.; supervision, A.F. and L.F.M. All authors have read and agreed to the published version of the manuscript.

Funding: This research received no external funding.

Conflicts of Interest: The authors declare to have no conflicts of interest.

\section{References}

1. Chalmers, D.; Dell, C.A. Applying One Health to the Study of Animal-Assisted Interventions. Ecohealth 2015, 12, 560-562. [CrossRef] [PubMed]

2. Santaniello, A.; Dicé, F.; Carratú, R.C.; Amato, A.; Fioretti, A.; Menna, L.F. Methodological and Terminological Issues in Animal-Assisted Interventions: An Umbrella Review of Systematic Reviews. Animals 2020, 10, 759. [CrossRef] [PubMed]

3. Hediger, K.; Meisser, A.; Zinsstag, J. A One Health Research Framework for Animal-Assisted Interventions. Int. J. Environ. Res. Public Health 2019, 16, 640. [CrossRef] [PubMed]

4. Menna, L.F.; Santaniello, A.; Todisco, M.; Amato, A.; Borrelli, L.; Scandurra, C.; Fioretti, A. The Human-Animal Relationship as the Focus of Animal-Assisted Interventions: A One Health Approach. Int. J. Environ. Res. Public Health 2019, 16, 3660. [CrossRef] [PubMed]

5. IAHAIO. IAHAIO White Paper 2014, Updated for 2018. The IAHAIO Definitions for Animal Assisted Intervention and Guidelines for Wellness of Animals Involved in AAI. 2018. Available online: https://iahaio.org/wp/wpcontent/uploads/2018/04/iahaio_wp_updated-2018-final.pdf (accessed on 3 June 2020).

6. Zafra-Tanaka, J.H.; Pacheco-Barrios, K.; Tellez, W.A.; Taype-Rondan, A. Effects of dog-assisted therapy in adults with dementia: A systematic review and meta-analysis. BMC Psychiatry 2019, 19, 41. [CrossRef]

7. Menna, L.F.; Santaniello, A.; Amato, A.; Ceparano, G.; Di Maggio, A.; Sansone, M.; Formisano, P.; Cimmino, I.; Perruolo, G.; Fioretti, A. Changes of Oxytocin and Serotonin Values in Dialysis Patients after Animal Assisted Activities (AAAs) with a Dog-A Preliminary Study. Animals 2019, 9, 526. [CrossRef]

8. Wijker, C.; Leontjevas, R.; Spek, A.; Enders-Slegers, M.J. Effects of Dog Assisted Therapy for Adults with Autism Spectrum Disorder: An Exploratory Randomized Controlled Trial. J. Autism Dev. Disord. 2019, 50, 2153-2163. [CrossRef]

9. Shen, R.Z.Z.; Xionga, P.; Choua, U.I.; Hall, B.J. "We need them as much as they need us": A systematic review of the qualitative evidence for possible mechanisms of effectiveness of animal-assisted intervention (AAI). Complement. Ther. Med. 2018, 41, 203-207. [CrossRef]

10. Christenson, E.S.; Ahmed, H.M.; Durand, C.M. Pasteurella multocida infection in solid organ transplantation. Lancet Infect. Dis. 2015, 15, 235-240. [CrossRef]

11. Santaniello, A.; Sansone, M.; Fioretti, A.; Menna, L.F. Systematic Review and Meta-Analysis of the Occurrence of ESKAPE Bacteria Group in Dogs, and the Related Zoonotic Risk in Animal-Assisted Therapy, and in Animal-Assisted Activity in the Health Context. Int. J. Environ. Res. Public Health 2020, 17, 3278. [CrossRef]

12. Gerardi, F.; Santaniello, A.; Del Prete, L.; Maurelli, M.P.; Menna, L.F.; Rinaldi, L. Parasitic infections in dogs involved in animal-assisted interventions. Ital. J. Anim. Sci. 2018, 1, 269-272. [CrossRef]

13. Maurelli, M.P.; Santaniello, A.; Fioretti, A.; Cringoli, G.; Rinaldi, L.; Menna, L.F. The Presence of Toxocara Eggs on Dog's Fur as Potential Zoonotic Risk in Animal-Assisted Interventions: A Systematic Review. Animals 2019, 9, 827. [CrossRef] [PubMed]

14. Ghasemzadeh, I.; Namazi, S.H. Review of bacterial and viral zoonotic infections transmitted by dogs. J. Med. Life 2015, 8, 1-5. 
15. Guay, D.R. Pet-assisted therapy in the nursing home setting: Potential for zoonosis. Am. J. Infect. Control 2001, 29, 178-186. [CrossRef]

16. Lefebvre, S.L.; Waltner-Toews, D.; Peregrine, A.S.; Reid-Smith, R.; Hodge, L.; Arroyo, L.G.; Weese, J.S. Prevalence of zoonotic agents in dogs visiting hospitalized people in Ontario: Implications for infection control. J. Hosp. Infect. 2006, 62, 458-466. [CrossRef]

17. Lefebvre, S.L.; Golab, G.C.; Christensen, E.; Castrodale, L.; Aureden, K.; Bialachowski, A.; Gumley, N.; Robinson, J.; Peregrine, A.; Benoit, M.; et al. Guidelines for animal-assisted interventions in health care facilities. Am. J. Infect. Control 2008, 36, 78-85. [CrossRef] [PubMed]

18. Guet-Revillet, H.; Levy, C.; Andriantahina, I.; Kalach, N.; Pierre, M.H.; Elbez-Rubinstein, A.; Boniface, C.; Berche, P.; Cohen, R.; Ferroni, A. Paediatric epidemiology of Pasteurella multocida meningitis in France and review of the literature. Eur. J. Clin. Microbiol. 2013, 32, 1111-1120. [CrossRef]

19. Godey, B.; Morandi, X.; Bourdinière, J.; Heurtin, C. Beware of dogs licking ears. Lancet 1999, $354,1267$. [CrossRef]

20. Wade, T.; Booy, R.; Teare, E.L.; Kroll, S. Pasteurella multocida meningitis in infancy (a lick may be as bad as a bite). Eur. J. Pediatrics 1999, 158, 875-878. [CrossRef]

21. Navarro-Navajas, A.; Ariza-Ordoñez, N.; Barrera, C. Pasteurella Multocida Bacteremia Associated with Contact With a Domestic Animal: Case Report. Rev. Chilena Infectol. 2019, 36, 667-669. [CrossRef]

22. Wilson, B.A.; Ho, M. Pasteurella multocida: From zoonosis to cellular microbiology. Clin. Microbiol. Rev. 2013, 26, 631-655. [CrossRef] [PubMed]

23. Caserza, L.; Piatti, G.; Bonaventura, A.; Liberale, L.; Carbone, F.; Dallegri, F.; Ottonello, L.; Gustinetti, G.; Del Bono, V.; Montecucco, F. Sepsis by Pasteurella multocida in an Elderly Immunocompetent Patient after a Cat Bite. Case Rep. Infect. Dis. 2017, 2017, 2527980. [CrossRef] [PubMed]

24. Bardou, M.; Honnorat, E.; Dubourg, G.; Couderc, C.; Fournier, P.E.; Seng, P.; Stein, A. Meningitis caused by Pasteurella multocida in a dog owner without a dog bite: Clonal lineage identification by MALDI-TOF mass spectrometry. BMC Res. Notes 2015, 8, 626. [CrossRef] [PubMed]

25. Maraki, S.; Kastanis, G.; Stafylaki, D.; Masunt, S.; Kapsetakis, P.; Scoulica, E. Pasteurella multocida wound infection transmitted by a pet dog. Germs 2018, 8, 214-217. [CrossRef]

26. Zarlasht, F.; Khan, M. A Case of Recurrent Pasteurella Bacteremia in an Immunocompetent Patient with No Animal Bite. Am. J. Case Rep. 2018, 19, 95-98. [CrossRef]

27. Ryan, J.M.; Feder, H.M. Dog licks baby. Baby gets Pasteurella multocida meningitis. Lancet 2019, 25, 393. [CrossRef]

28. Abreu, F.; Rodríguez-Lucas, C.; Rodicio, M.R.; Vela, A.I.; Fernández-Garayzábal, J.F.; Leiva, P.S.; Cuesta, F.; Cid, D.; Fernández, J. Human Pasteurella multocida Infection with Likely Zoonotic Transmission from a Pet Dog, Spain. Emerg. Infect. Dis. 2018, 24, 1145-1146. [CrossRef]

29. Ferreira, R.; Martins, J.; Adrega, T.; Pinto, S.; Nunes, S.; Pancas, R.; Gonzaga, A.; Santos, J. Purulenta pericarditis and Pasteurella multocida: An extremely rare entity. Rev. Port. Cardiol. 2018, 37, 353.e1-353.e4. [CrossRef]

30. Aljameely, A.; Wali, G. Pasteurella multocida Septic Shock: Case Report and Literature Review. Case Rep. Infect. Dis. 2019, 3, 1964161. [CrossRef]

31. Dousse, F.; Thomann, A.; Brodard, I.; Korczak, B.M.; Schlatter, Y.; Kuhnert, P.; Miserez, R.; Frey, J. Routine phenotypic identification of bacterial species of the family Pasteurellaceae isolated from animals. J. Vet. Diagn. Investig. 2008, 20, 716-724. [CrossRef]

32. Forsblom, B.; Sarkiala-Kessel, E.; Kanervo, A.; Väisänen, M.L.; Helander, M.; Jousimies-Somer, H. Characterization of aerobic Gram-negative bacteria from subgingival sites of dogs-potential bite wound pathogens. J. Med. Microbiol. 2002, 51, 207-220. [CrossRef] [PubMed]

33. Król, J.; Bania, J.; Florek, M.; Pliszczak-Król, A.; Staroniewicz, Z. Polymerase chain reaction-based identification of clinically relevant Pasteurellaceae isolated from cats and dogs in Poland. J. Vet. Diagn. Investig. 2011, 23, 532-537. [CrossRef] [PubMed]

34. Kabacoff, R.I. R in Action-Data Analysis and Graphics with R; Manning Publications: Shelter Island, NY, USA, 2011.

35. R Core Team. R: A Language and Environment for Statistical Computing; R Foundation for Statistical Computing: Vienna, Austria, 2019. Available online: https://www.R-project.org/ (accessed on 5 July 2020).

36. Toutenburg, H. Shalabh. Statistical Analysis of Designed Experiments, 3rd ed.; Springer Science+Business Media, LLC: Berlin/Heidelberg, Germany, 2009. 
37. Peng, Z.; Wang, X.; Zhou, R.; Chen, H.; Wilson, B.A.; Wu, B. Pasteurella multocida: Genotypes and Genomics. Microbiol. Mol. Biol. Rev. 2019, 83, e00014-19. [CrossRef]

38. Menna, L.F.; Santaniello, A.; Gerardi, F.; Sansone, M.; Di Maggio, A.; Di Palma, A.; Perruolo, G.; D’Esposito, V.; Formisano, P. Efficacy of animal-assisted therapy adapted to reality orientation therapy: Measurement of salivary cortisol. Psychogeriatrics 2019, 19, 510-512. [CrossRef] [PubMed]

39. Menna, L.F.; Santaniello, A.; Gerardi, F.; Di Maggio, A.; Milan, G. Evaluation of the efficacy of animal-assisted therapy based on the reality orientation therapy protocol in Alzheimer's disease patients: A pilot study. Psychogeriatrics 2016, 16, 240-246. [CrossRef]

40. Elad, D. Immunocompromised patients and their pets: Still best friends? Vet. J. 2013, 197, 662-669. [CrossRef]

41. Overgaauw, P.A.M.; Vinke, C.M.; Hagen, M.A.E.V.; Lipman, L.J.A. A One Health Perspective on the Human-Companion Animal Relationship with Emphasis on Zoonotic Aspects. Int. J. Environ. Res. Public Health 2020, 17, 3789. [CrossRef]

42. Murthy, R.; Bearman, G.; Brown, S.; Bryant, K.; Chinn, R.; Hewlett, A.; George, B.G.; Goldstein, E.J.; Holzmann-Pazgal, G.; Rupp, M.E.; et al. Animals in healthcare facilities: Recommendations to minimize potential risks. Infect. Control. Hosp. Epidemiol. 2015, 36, 495-516. [CrossRef]

43. Linder, D.E.; Siebens, H.C.; Mueller, M.K.; Gibbs, D.M.; Freeman, L.M. Animal-assisted interventions: A national survey of health and safety policies in hospitals, eldercare facilities, and therapy animal organizations. Am. J. Infect. Control 2017, 45, 883-887. [CrossRef]

44. Hardin, P.; Brown, J.; Wright, M.E. Prevention of transmitted infections in a pet therapy program: An exemplar. Am. J. Infect. Control 2016, 44, 846-850. [CrossRef]

45. The Society for Healthcare Epidemiology of America (SHEA). Available online: https://www.shea-online. org/index.php/about/mission-history (accessed on 27 June 2020).

(C) 2020 by the authors. Licensee MDPI, Basel, Switzerland. This article is an open access article distributed under the terms and conditions of the Creative Commons Attribution (CC BY) license (http://creativecommons.org/licenses/by/4.0/). 